\title{
PENGARUH MOTIVASI KERJA DAN IKLIM ORGANISASI TERHADAP KINERJA PEGAWAI TATA USAHA UNIVERSITAS ISLAM KALIMANTAN MUHAMMAD ARSYAD AL BANJARI BANJARMASIN
}

\author{
Nasrullah, Sulastini, Muhammad Harlie \\ Program Studi Magister Manajemen \\ Universitas Islam Kalimantan \\ Jl. Adhyaksi No. 2 Kayutangi, Banjarmasin \\ E-mail: nasrullah.nasrullah
}

\begin{abstract}
The Role of Climate Organizations and motivations to improve employee performance are very important. This study aims to find out what are the factors that affect the performance of administrative staff at the Islamic University of Kalimantan Muhammad Arsyad Al Banjari Banjarmasin. This study uses quantitative methods, with a total sample of 60 respondents. The data analysis method used is by using multiple linear regression. The results of the study on the effect of work motivation and Organizational Climate on the performance of Administrative staff at the Islamic University of Kalimantan Banjarmasin showed the following results: The first hypothesis states the influence of motivation and Organizational Climate together have a positive influence on the performance of Administrative employees but not significant (meaningless), The second hypothesis states that the influence of motivation partially has a positive and significant influence on the performance of administrative staff of the Islamic University of Borneo. The third hypothesis states that the influence of Organizational Climate partially has a positive and significant influence on the performance of administrative staff of the Islamic University of Kalimantan Banjarmasin not proven, because the effect is negative and not significant. So it can be concluded that only motivation has a significant effect on the performance of administrative staff of the Islamic University of Kalimantan.
\end{abstract}

Keywords: Motivation, Organizational Climate, Administrative Performance

\begin{abstract}
Abstrak
Peran dari Iklim Organisasi dan motivasi untuk meningkatkan kinerja pegawai amatlah penting. Penelitian ini bertujuan untuk mengetahui faktor-faktor apa sajakah yang mempengaruhi kinerja pegawai Tata Usaha di Universitas Islam Kalimantan Muhammad Arsyad Al Banjari Banjarmasin. Penelitian ini menggunakan metode kuantitatif, dengan jumlah sampel sebanyak 60 responden. Metode analisis data yang digunakan adalah dengan menggunakan regresi linear berganda. Hasil penelitian tentang pengaruh motivasi kerja dan Iklim Organisasi terhadap kinerja pegawai Tata Usaha di Universitas Islam Kalimantan Banjarmasin menunjukkan hasil sebagai berikut: Hipotesis pertama menyatakan pengaruh motivasi dan Iklim Organisasi secara bersama-sama mempunyai pengaruh positif terhadap kinerja pegawai Tata Usaha tetapi tidak signifikan (tidak bermakna), Hipotesis kedua menyatakan pengaruh motivasi secara parsial mempunyai pengaruh positif dan signifikan terhadap kinerja pegawai Tata Usaha Universitas Islam Kalimantan. Hipotesis ketiga menyatakan pengaruh Iklim Organisasi separa parsial mempunyai pengaruh positif dan signifikan terhadap kinerja pegawai Tata Usaha Universitas Islam Kalimantan Banjarmasin tidak terbukti, karena pengaruhnya bernilai negatif dan tidak signifikan. Sehingga dapat disimpulkan bahwa hanya motivasi yang berpengaruh signifikan terhadap kinerja pegawai tata usaha Universitas Islam Kalimantan.
\end{abstract}

Kata Kunci : Motivasi, Iklim Organisasi, Kinerja Tata Usaha 


\section{PENDAHULUAN}

Seiring dengan perkembangan kampus yang demikian pesat ada beberapa Pekerjaan rumah yang perlu digarisbawahi bagi manajemen UNISKA MAB Banjarmasin mengenai rendahnya motivasi dan Iklim Organisasi untuk meningkatkan kinerja pegawai Tata Usaha. secara absensi ada penurunan kinerja pegawai Tata Usaha di Universitas Islam Kalimantan Muhammad Arsyad Al Banjari Banjarmasin seperti data absensi pegawai dibawah ini :

Tabel 1. Prosentasi Absensi Karyawan

\begin{tabular}{|l|l|l|l|}
\hline No & Bulan & Absensi & Keterangan \\
\hline 1 & Januari & $99,36 \%$ & $\begin{array}{l}\text { Naik 0,02\% dari } \\
\text { Desember 2017, } \\
99,34 \%\end{array}$ \\
\hline 2 & Februari & $99,34 \%$ & Turun 0,02\% \\
\hline 3 & Maret & $99,29 \%$ & Turun 0,05\% \\
\hline 4 & April & $99,21 \%$ & Turun 0,08\% \\
\hline 5 & Mei & $99,36 \%$ & $\begin{array}{l}\text { Naik 0,02\% dari } \\
\text { Desember 2017, } \\
99,34 \%\end{array}$ \\
\hline
\end{tabular}

Sumber: Kepegawaian UNISKA (2018)

Dari tabel diatas secara dinamis terjadi penurunan tingkat absensi pegawai, terutama pada bulan Januari sampai bulan April 2018, pada bulan januari ke pebruari tahun 2018 mengalami penurunan absensi sebesar 0,02 $\%$, dari bulan pebruari ke bulan maret 2018 mengalami penurunan absensi sebesar $0,05 \%$ dan dari bulam maret ke bulan april 2018 mengalami penurunan absensi sebesar $0,08 \%$, akibat yang mendasar pada penurunan absensi pegawai ini masih belum diketahui apakah ada hubungannya dengan motivasi dan iklim organisasi yang sedang berjalan atau disebabkan karena banyaknya tanggal merah atau mendekati bulan ramadhan namun yang jelas kinerja pegawai Tata Usaha yang menurun berpengaruh terhadap daya saing Universitas Islam
Kalimantan Muhammad Arsyad Al Banjari Banjarmasin. Dengan alasan tersebut diatas penulis merasa perlu untuk menggarap penelitian ini dengan memfokuskan pada motivasi dan Iklim Organisasi terhadap kinerja pegawai Tata Usaha.

Motivasi merupakan satu penggerak dari dalam hati seseorang untuk melakukan atau mencapai sesuatu tujuan. Motivasi juga bisa dikatakan sebagai rencana atau keinginan untuk menuju kesuksesan dan menghindari kegagalan hidup. Dengan kata lain pengaruh motivasi terhadap individu/seseorang mempunyai kekuatan lebih untuk memperoleh kesuksesan dalam meningkatkan jasa pelayanan di suatu lembaga atau organisasi, seperti lembaga yang mengutamakan kinerja tersebut, supaya organisasi/ lembaga dapat mencapai tujuannya, dengan kata lain lembaga yang terfokus atau mengutamakan pada kinerja yang baik, seperti Lembaga Pendidikan memerlukan motivasi kerja pegawai dan Iklim Organisasi yang baik pula, sehingga menghasilkan layanan yang berkualitas pula. terdapat dua faktor utama yang menjadi penentu perilaku individu dalam menghasilkan kinerja. Faktor tersebut adalah faktor organisasional dan faktor individual. Salah satu faktor organisasional yang penting adalah iklim organisasi. Iklim organisasi yang kondusif akan mendorong kenyamanan anggota organisasi dalam berkegiatan, konsentrasi dalam bekerja, sehingga mampu menghasilkan kinerja yang tinggi.

Hal ini didukung oleh Hasil penelitian (Wahyuli, 2007) yang menunjukkan adanya hubungan yang sangat signifikan antara Iklim Organisasi dengan Kenerja Pegawai. Hal ini berarti semakin kondusif iklim organisasi dalam suatu perusahaan akan diikuti dengan tingginya nilai-nilai Iklim Organisasi Perusahaan. 
Organisasi harus percaya bahwa untuk mencapai keunggulannya, perlu mengusahakan kinerja individu yang setinggi-tingginya. Pada dasarnya kinerja individu mempengaruhi kinerja tim dan pada akhirnya mempengaruhi kinerja organisasi secara keseluruhan. Perilaku yang menjadi tuntutan organisasi tidak hanya perilaku inrole tetapi juga perilaku extra-role. Perilaku extra-role sangat penting artinya karena memberikan manfaat yang lebih baik untuk menunjang keberlangsungan organisasi (Oguz, 2010). Perilaku extra-role di dalam organisasi dikenal dengan istilah Iklim Organisasi.

Iklim Organisasi merupakan kontribusi individu yang melebihi tuntutan peran di tempat kerja. Iklim Organisasi ini melibatkan beberapa perilaku meliputi perilaku menolong orang lain, menjadi sukarelawan (volunteer) untuk tugas-tugas ekstra, patuh terhadap aturan dan prosedur di tempat kerja. Perilaku-perilaku ini menggambarkan "nilai tambah Pegawai" yang merupakan salah satu bentuk perilaku prososial, yaitu perilaku sosial positif, konstruktif dan bermakna membantu (Aldag \& Resckhe, 1997) Iklim Organisasi merupakan istilah yang digunakan untuk mengidentifikasi perilaku yang dilakukan Pegawai diluar tugas utamanya, akan tetapi perilaku ini diinginkan dan berguna bagi organisasi tersebut (Neami \& Shokrkon, 2004).

Definisi ini juga menganggap bahwa pelaku Iklim Organisasi bertujuan untuk menguntungkan organisasi. Dari beberapa definisi sebelumnya dapat disimpulkan, bahwa Iklim Organisasi merupakan: (a) Perilaku yang bersifat sukarela, bukan merupakan tindakan yang terpaksa terhadap hal-hal yang mengedepankan kepentingan organisasi; (b) Perilaku individu sebagai wujud dari kepuasan berdasarkan kinerja, tidak diperintahkan secara formal; (c) Tidak berkaitan secara langsung dan terangterangan dengan sistem reward formal.

Iklim Organisasi merupakan kondisi yang banyak diharapkan organisasi untuk dimiliki perusahaannya. Hal tersebut dikarenakan Iklim Organisasi dianggap menguntungkan organisasi yang tidak bisa ditumbuhkan dengan basis kewajiban peran formal maupun dengan bentuk kontrak atau rekompensasi. Jika dilihat lebih jauh, iklim organisasi adalah faktor yang memberikan sumbangan pada hasil kerja organisasi secara keseluruhan. Perilaku ini cenderung melihat pegawai sebagai anggota organisasi dibanding sebagai seorang individu.

Sebagai anggota organisasi, individu diharapkan memiliki kemampuan dalam menjaga dan meningkatkan interaksi dengan lingkungan sosial tanpa mengharapkan imbalan tertentu. iklim organisasi merupakan suatu perilaku positif individu sebagai anggota organisasi dalam bentuk kesediaan secara sadar dan sukarela untuk bekerja dan memberikan kontribusi pada organisasi lebih daripada apa yang dituntut secara formal dalam organisasi. iklim organisasi ini memiliki peran penting untuk keberhasilan organisasi.

Adapun faktor individual yang berpengaruh terhadap perilaku individu adalah motivasi yang sifatnya harus dibangun terlebih dahulu baik secara intrinsic dan ekstrinsic. Motivasi yang bersifat intinsik adalah manakala sifat pekerjaan itu sendiri yang membuat seorang termotivasi, orang tersebut mendapat kepuasan dengan melakukan pekerjaan tersebut bukan karena rangsangan lain seperti status ataupun uang atau bisa juga dikatakan seorang melakukan kesukaannya. Sedangkan motivasi ekstrinsik adalah manakala elemen elemen diluar pekerjaan yang melekat di pekerjaan tersebut menjadi faktor utama yang membuat seorang 
termotivasi seperti status ataupun kompensasi.

Sedangkan Iklim Organisasi yang dibangun tentunya berdasarkan pendekatan persuasive, dimana seorang pemimpin dituntut harus dapat dan mengetahui kemampuan pegawainya dalam bekerja, sehingga nantinya dapat membujuk dan merayu kepada semua pegawai, serta memudahkan pemimpin dalam bekerja, terutama meningkatkan merotasi dan kualitas kerjanya dalam memberikan pelayanan terhadap pelangga yang datang ke Lembaga Pendidikan tersebut.

Dengan motivasi dan Iklim Organisasi yang baik, tentunya akan menghasilkan kinerja yang berkualitas pula, karena suatu organisasi yang mengandalkan pada kinerja, kualitas pelayanan harus tetap diutamakan dalam menghasilkan pendapatan yang optimal.

Dari alasan diatas dapat disimpulkan, bahwa motivasi kerja pegawai dan Iklim Organisasi sangat berpengaruh sekali terhadap kinerja, sehingga penulis tertarik dalam penelitian ini mengambil judul "Pengaruh Motivasi Kerja dan Iklim Organisasi terhadap Kinerja pegawai Tata Usaha Universitas Islam Kalimantan Muhammad Arsyad Al Banjari Banjarmasin.

\section{TINJAUAN PUSTAKA}

\section{Kajian Empirik}

Penelitian yang dilakukan oleh Rizky Putradari (2011) Universitas Sumatera Utara melakukan penelitian dengan judul thesis "Pengaruh Iklim Organisasi dan Motivasi Kerja TerhadapKinerja pegawai Tata Usaha PT. Bank Syariah Mandiri, Tbk Cabang Petisah Medan". Penelitian ini bertujuan untuk mengetahui apakah Iklim Organisasi dan motivasi berpengaruh terhadap peningkatan kinerja pegawai di Bank Syariah Mandiri Medan. Hasil penelitian menunjukkan Menunjukan bahwa Iklim Organisasi dan motivasi berpengaruh sangat signifikan terhadap kinerja pegawai . diketahui bahwa motivasi yang paling dominan mempengaruhi kinerja pegawai. Berdasarkan Uji Parsial (Uji t) diketahui bahwa Iklim Organisasi berpengaruh signifikan terhadap motivasi.

Penelitian yang dilakukan oleh Suharyanto (2011) mahasiswa Pasca Sarjana Universitas Narotama Surabaya melakukan penelitian dengan judul "PengaruhIklim Organisasi dan Motivasi Terhadap Kinerja Pegawai di Universitas Narotama Surabaya". Hasil penelitian Iklim Organisasi dan motivasi berpengaruh secara signifikan terhadap kinerja pegawai. Secara persial Iklim Organisasi berpengaruh terhadap kinerja pegawai (t hitung) sebesar 3,664 dan (t tabel) 1,96 serta nilai signifikansi sebesar $0,000<$ 0,05 . Sedangkan motivasi juga secara parsial sangat berpengaruh secara signifikan terhadap kinerja pegawai dari ( $\mathrm{t}$ hitung) sebesar 4,33 dan (t tabel) 1,96 serta nilai signifikansi sebesar $0,000<0,05$.

Penelitian yang dilakukan oleh Suparno (2012) mahasiswa Pasca Sarjana Universitas Negeri Semarang melakukan penelitian dengan judul "Pengaruh Motivasi dan Iklim Organisasi Terhadap Kinerja Guru SMPN di Kecamatan Pemalang Kabupaten Pemalang”. Hasil penelitian Variabel motivasi dan Iklim Organisasi secara bersama-sama berpengaruh positif dan signifikan terhadap kinerja guru SMPN Kecamatan Pemalang Kabupaten Pemalang. Variabel motivasi adalah faktor yang paling dominan terhadap kinerja pegawai. variabel motivasi merupakan variabel yang berpengaruh paling dominan terhadap kinerja guru SMPN Kecamatan Pemalang Kabupaten Pemalang.

Kajian Teoritis 


\section{Kinerja pegawai}

Menurut Achmad S Ruky (2002; 48), yang menyatakan bahwa kinerja, merupakan tingkat pencapaian hasil dari seseorang, yang dapat diukur dengan indikatornya, meliputi: 1). Terhadap kuantitas pekerjaannya, 2).Terhadap kualitas hasil kerjanya, 3). Terhadap Kejujurannya, 4). Terhadap ketaatannya, 5). Terhadap Inisiatifnya, dan 6). Terhadap kecerdasannya.

Bagi organisasi, hasil penilaian kinerja dipakai sebagai pertimbangan untuk pengambilan keputusan tentang berbagai hal seperti kebutuhan pendidikan dan pelatihan, seleksi, penempatan dan lainnya.

Bagi pegawai, penilaian tersebut memberikan feed back tentang pelaksanaan kerja, misalnya kemampuan, potensi dan lainnya agar dapat diketahui kelebihan dan kekurangannya sehingga pegawai tersebut diharapkan akan mempertahankan kelebihannya dan memperbaiki kekurangannya sehingga di waktu mendatang akan meningkat hasil kerjanya.

\section{Motivasi}

Motivasi menurut Soehardi Sigit (2003 ;33) adalah dorongan dari dalam dirinya yang tercermin dalam perilakunya. Dorongan ini timbul oleh adanya insentif (rangsangan) atau stimulus yang harus diraih untuk memenuhi kebutuhannya. Jika rangsangan atau stimulus yang sudah diraih dapat memenuhi kebutuhannya maka puaslah seseorang. Jika tidak, maka seseorang masih dalam keadaan tegang (tension). Kekuatan motivasi yang ditunjukkan oleh seseorang dalam menghadapi situasi tertentu akan berbeda dengan orang lain yang menghadapi situasi yang sama.

Dalam kehidupan organisasi, sasaran utama pemberian motivasi oleh Yayasan kepada bawahan adalah meningkatkan prestasi kerja guna mencapai tujuan dan sasaran organisasi. Tetapi, prestasi kerja tidak dapat ditingkatkan hanya melalui pemberian motivasi saja karena la merupakan pertahan antara kemampuan dan motivasi.

\section{Iklim organisasi}

Sopiah,(2008) mendefinisikan bahwa iklim organisasi merupakan hal yang amat penting bagi keberhasilan suatu organisasi dan iklim suatu organisasi akan sangat berbeda dengan iklim organisasi lainnya, karena hal tersebut berkaitan dengan kondisi lingkungan kerja masing $\neg$ masing organisasi. Iklim organisasi juga merupakan konsep deskriptif yang berdasarkan pada persepsi lingkungan sosial anggota organisasi

( Suharsaputra, Udar, 2013: 82).

Berdasarkan penjelasan di atas, maka hipotesis penelitian ini dapat dirumuskan sebagai berikut:

H1 : Terdapat pengaruh yang signifikan Motivasi terhadap Kinerja karyawan pada Universitas Islam Kalimantan Muhammad Arsyad Al-Banjari Banjarmasin.

H2 : Terdapat pengaruh yang signifikan Kompensasi terhadap Kinerja karyawan pada Universitas Islam Kalimantan Muhammad Arsyad AlBanjari Banjarmasin.

H3 : Motivasi dan Kompensasi secara bersama-sama berpengaruh signifikan terhadap Kinerja karyawan pada Universitas Islam Kalimantan Muhammad Arsyad Al-Banjari Banjarmasin. 


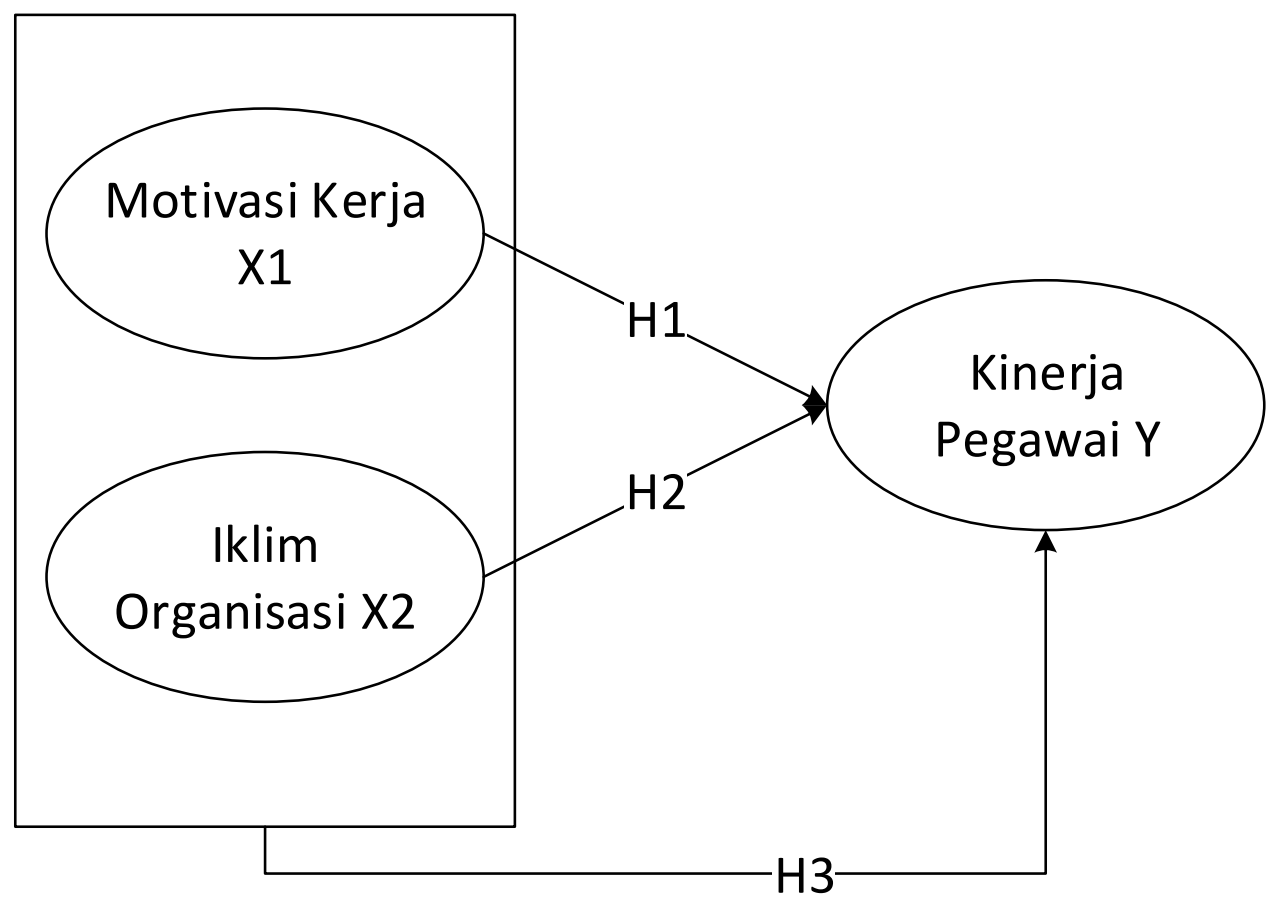

Gambar 1. Model Kerangka Berpikir

\section{METODE PENELITIAN}

Jenis Penelitian

Penelitian ini menggunakan jenis penelitian kuantitatif dengan tujuan untuk melihat pengaruh motivasi; iklim organisasi terhadap kinerja pegawai.

\section{Lokasi dan waktu Penelitian}

Lokasi dalam penelitian ini dilakukan di Universitas Islam Kalimantan Muhammad arsyad Al-Banjari Banjarmasin.

\section{Populasi dan Ukuran Sampel Penelitian}

Sampel dalam penelitian ini adalah seluruh pegawai tata usaha pada Universitas Islam Kalimantan Muhammad arsyad AlBanjari Banjarmasin yang berjumlah 55 orang. Berdasarkan jumlah yang ada, seluruh populasi dijadikan sampel. Teknik pengambilan data dalam penelitian ini menggunakan metode Sampling Jenuh (Sensus), yaitu teknik penentuan sampel bila semua anggota populasi digunakan sebagai sampel.

\section{Teknik Pengumpulan Data}

Teknik Pengumpulan data dalam penelitian ini dengan melakukan pengisian kuesioner dari responden atau sampel yang sudah ditentukan sebelumnya, serta melakukan wawancara dan observasi langsung pada objek peneltian agar informasi didapat secara maksimal dan objektif.

\section{Metode Analisis Data}

Metode penelitian ini adalah deskriptif kuantitatif ddengan menggunakan pendekatan statistic dari hasil kuesioner yang telah didapat dan diolah menggunakan regresi linier berganda.

\section{HASIL DAN PEMBAHASAN}

Hasil

Berdasarkan tabel 4 di atas Perhitungan regresi linear berganda dengan menggunakan program SPSS menghasilkan: $\quad Y=2,115+0,498 \mathrm{X}$ $0,0469 \mathrm{X}_{2}$. 
Tabel 2. Ringkasan Hasil Analisis Regresi Linear

\begin{tabular}{|l|r|r|r|r|l|}
\hline \multicolumn{1}{|c|}{ Variabel } & $\begin{array}{c}\text { Koefisien } \\
\text { Regresi }\end{array}$ & \multicolumn{1}{c|}{ Beta } & \multicolumn{1}{c|}{ 'hituna } & \multicolumn{1}{c|}{ SigT } & Keterangan \\
\hline Konstanta (b0) & 2,775 & & & & \\
\hline Motivasi (X1) & 0,498 & 0,301 & 1,958 & 0,056 & Signifikan \\
\hline Iklim Organisasi (X2) & $-0,0469$ & $-0,054$ & $-0,354$ & 0,725 & tidak signifikan \\
\hline $\begin{array}{l}\text { Adjusted R } \\
\text { Square }=0,042 \\
\text { R Square =0,077 } \\
\text { R =0,278 }\end{array}$ & & & F tabel $=3,1751$ t tabel $=1,675$ \\
F hitung = 2,172 & & & & & \\
SignifF $=0,124$ & & & & & \\
\hline
\end{tabular}

Sumber: Data diolah (2018)

1) Konstanta $\left(b_{0}\right)$

Nilai konstanta sebesar 2,775 berarti bahwa jika tidak ada variabel bebas yang terdiri dari variabel bebas yaitu variabel Motivasi $\left(\mathrm{X}_{1}\right)$ dan variabel Iklim Organisasi $\left(\mathrm{X}_{2}\right)$, yang mempengaruhi Kinerja pegawai Tata Usaha maka Kinerja pegawai Tata Usaha akan mempunyai harga sebesar 2,775. ini berarti ada variabel lain yang dapat mempengaruhi kinerja pegawai Tata Usaha sebesar 2,775.

\section{2) Koefisien Regresi Motivasi $\left(b_{1}\right)$}

Variabel Motivasi $\left(\mathrm{X}_{1}\right)$ mempunyai pengaruh yang positif terhadap Kinerja pegawai Tata Usaha. Dengan koefisien regresi sebesar 0,498 yang artinya apabila variabel Motivasi meningkat sebesar 1 satuan, maka Kinerja pegawai Tata Usaha akan meningkat sebesar 0,498 satuan dengan asumsi bahwa pada variabel Iklim Organisasi $\left(\mathrm{X}_{2}\right)$ dalam kondisi konstan.

\section{Variabel Iklim Organisasi $\left(\mathrm{X}_{2}\right)$} mempunyai pengaruh yang negatif terhadap Kinerja pegawai Tata Usaha. Dengan koefisien regresi sebesar -0,0469 yang artinya apabila variabel Motivasi meningkat sebesar 1 satuan, maka Kinerja pegawai Tata Usaha akan menurun sebesar -0,0469 dengan asumsi bahwa pada variabel Motivasi $\left(\mathrm{X}_{1}\right)$ dalam kondisi konstan. Dengan adanya pengaruh yang negatif ini, berarti antara variabel Iklim Organisasi dan Kinerja pegawai Tata Usaha menunjukkan hubungan yang tidak searah. Jika variabel Iklim Organisasi meningkat, mengakibatkan Kinerja pegawai Tata Usaha akan menurun, begitu pula sebaliknya.

Dari tabel 5 pada tabel ringkasan tersebut diketahui bahwa hasil pengujian secara parsial menunjukkan bahwa pengaruh motivasi (X1) terhadap kinerja karyawan administrasi di Universitas islam Kalimantan menunjukkan pengaruh yang lebih besar. Meskipun demikian pengaruh Kompensasi (X2) menunjukkan angka yang relative kecil daripada pengujian serentak. Hal tersebut mengindikasikan bahwa kompensasi yang sekarang disediakan sudah mencukupi sehingga menambahkan jumlah kompensasi akan memberikan peningkatan yang lebih kecil kepada kinerja karyawan jika dibandingkan dengan motivasi kinerja.

\section{KESIMPULAN DAN SARAN}

\section{Kesimpulan}

Berdasarkan hasil penelitian tentang pengaruh motivasi kerja dan Iklim Organisasi terhadap kinerja pegawai Tata Usaha di 
Universitas Islam Kalimantan Banjarmasin, maka dapat diambil kesimpulan sebagai berikut:

\section{Hipotesis Pertama}

Hipotesis pertama menyatakan adanya hubungan positif dan signifikan antara motivasi dan Iklim Organisasi, hipotesis terdukung karena hasil uji korelasi membuktikan bahwa terdapat hubungan positif dan signifikan antara motivasi dan Iklim Organisasi tetapi tidak terlalu tinggi/ sedang saja.

\section{Hipotesis Kedua}

Hipotesis Kedua menyatakan pengaruh motivasi secara parsial mempunyai pengaruh positif dan signifikan terhadap kinerja pegawai Tata UsahaUniversitas Islam Kalimantan Banjarmasin.

\section{Hipotesis Ketiga}

Hipotesis Ketiga menyatakan pengaruh Iklim Organisasi separa parsial mempunyai pengaruh positif dan signifikan terhadap kinerja pegawai Tata UsahaUniversitas Islam Kalimantan Banjarmasin tidak terbukti, karena pengaruhnya bernilai negatif dan tidak signifikan.

\section{Saran}

Berdasarkan kesimpulan diatas, maka penulis mengajukan saran yang diharapkan dapat bermanfaat bagi Universitas Islam Kalimantan Banjarmasin berkaitan dengan pengaruh motivasi dan Iklim Organisasi terhadap kinerja pegawai Tata Usaha sebagai berikut:

Kebijaksanaan dan administrasi organisasi yang dilandasi kepentingan bersama harus mencerminkan aspirasi Pegawai Tata Usaha sehingga kebijaksanaan itu dapat dilaksanakan dengan baik, hubungan kerja antar Pegawai Tata Usaha harus diciptakan dan ditingkatkan agar terjalin kerjasama yang baik antar Pegawai Tata Usaha, hal tersebut tentunya mendukung kinerja pegawai Tata Usaha. Perhatian Yayasan kepada Pegawai Tata Usaha diupayakan secara adil merata sehingga memberikan efek positif, memberikan lebih banyak kesempatan pada Pegawai Tata Usaha untuk menuangkan ideide dalam pelaksanaan pekerjaan akan memacu Pegawai Tata Usaha bekerja lebih baik serta mempromosikan Pegawai Tata Usaha yang berprestasi akan lebih meningkatkan kinerja di Universitas Islam Kalimantan Banjarmasin.

\section{Keterbatasan}

Penelitian ini terdapat banyak keterbatasan baik berupa waktu dalam penulisannya.

Hasil penelitian ini tidak bisa diberlakukan untuk umum dan hanya bisa diberlakukan untuk Universitas Islam Kalimantan Muhammad Arsyad Al-Banjari Banjarmasin.

Hasil penelitian ini minimal dapat menjadi masukan bagi Universitas Islam Kalimantan Muhammad Arsyad Al-Banjari Banjarmasin dalam rangka meningkatkan Kinerja pegawai tata usaha yang bekerja di Universitas Islam Kalimantan Muhammad Arsyad Al-Banjari Banjarmasin dan untuk mengetahui bagaimana kondisi motivasi dan iklim organisasi yang sedang berlangsung.

\section{DAFTAR PUSTAKA}

Achmad S Ruky, 2002, Sistem Manajemen Kinerja, Penerbit PT. Gramedia Pustaka Utama, Jakarta

Agus Waryanto, 1998, Pengaruh Motivasi Terhadap Peningkatan Kinerja Aparat di Lingkungan Secretariat Wilayah/ Daerah Tingkat I Jawa Tengah

Algifari, 1997, Analisis Regresi, Kasus dan 
Teori, Penerbit BPTP, Yogyakart

Algifari, 2000, Analisis Regresi, Teori,

Kasus dan Solusi, Penerbit BPFE, Banjarmasin.

Aribowo Prijosaksono, 2004, Iklim

Organisasi dan Motivasi. Jakarta: Ghalia Indonesia.

Bass, B.M. and Avolio BJ, 1985, Transformasional Leadership

Development : Manual for the Multifactor Leadership Questioner, Palo Alto,Consulting Psychologist Press Inc, California

Burn, JM, 1978, Leadership, Harper \& Row, New York.

Clayton Aldeefer, 1997, Educational

Reseach, Pearson, New York.

Cooper and Emoy, 1995, Business Reseach Methods, McGrraw-Hill, Irwin, Boston.

Darmawan Wibisono, 2000, Riset Bisnis, BPFE, Banjarmasin.

Dubin, 1967, Method for Policy Reseach, Sage Publication, Baverly Hill-London.

Frederick Herzberg, 2011, Program Evaluation, Pearson, New York.

Gary Dessler, 1997, Esensi Iklim Organisasi, alih bahasa Aris Ananda, Penerbit Mitra Utama, Jakarta.

Ginson et all, 1996, Basic Statistic for Business and Economic, Fifth Edition, McGraw-Hill.

H. Noeng Muhadjir 2000, Metodologi Penelitian Kualitatif, Rake Sarasun, Banjarmasin.

Hemphill, 1954, Basic Statistic for Social Reseach, McMillan Publishing, Co Inc.

JJJ. Wuisman, 1996, Penelitian Ilmu-Ilmu Sosial: Asas-asas, Jilid I, Lembaga Penerbit Fakultas Ekonomi Universitas Indonesia, Jakarta.

John W. Creswell, 1994, Research Desaign: Quantitative and Qualitative Approachs, Sage Publication, hal 4.

Kerlinger, 1973, Foundation of Behavioral Research, Victoria, Thomson Learning.

Lawler and Porter, 1967, Handbook of Survey Research, Academics, Press, Inc.

Manulang, 1981, Manajemen Personalia, Penerbit Balai Aksara, Jakarta.
Mairr, 1965, Research Methods in Sociology, Cengange Leaning Australia,

Masri S dan Sofian Effendi, 1981 dan 1995, Metode Penelitian Survey, LP3ES, Jakarta.

Moh As'ad, 1998, Psikologi Industn, Penerbit Liberty, Banjarmasin

Pawar and Eatman, 1997, Social Reseach Methods: Qualitative and Quantitative Approaches, Third Edition, USA: Allyn and Baconn, hal 60.

Pawar, BS, and Eastman, KK, 1997, The Nature and Implication of Contextual Influences on Transformasional Leadership: A Conceptual Examination. Academy of Management Review, Vol 22, No. 180-190.

Robbins, 1989, Teori Organisasi: Struktur, Desain, dan Aplikasi, Penerbit Arcan, Jakarta.

Robbins, Stephen P, 1996, Perilaku Organisasi-Konsep, Kontroversi, Aplikasi, Jakarta: PT. Prenhallindo.

Simamora, 1997, Manajemen Sumber Daya Manusia, Penerbit STIE YKPN, Banjarmasin.

Soehardi Sigit, 2001, Pengantar Metodologi Penelitian, Penerbit BPFE UST, Banjarmasin

Sondang P Siagian, 1995, Manajemen Sumber Daya Manusia, Penerbit Bumi Aksara, Jakarta

Sritua Arief, 1993, Metodologi Penelitian Ekonomi, Penerbit U1-Press, Jakarta

Sugiyono, 2002, Metodologi Penelitian Bisnis, Penerbit CV. Alfabeta, Bandung

Suharsimi Arikunto, 1995, Manajemen Penelitian, Penerbit Rineka Cipta, Jakarta

Sumadi Suryabrata, 2002, Metodologi Penelitian, Rajawali Press, Jakarta.

Terry 1960, Asas-Asas Manajemen (Principle of Management), Bandung : Penerbit ALUMNI.

Thoha, 2001, Dimensi-Dimensi Prima Administrasi Negara, Banjarmasin : Fisipol

Tjahjo Retno Adhi, 2005, Pengaruh Motivasi dan Gaya Iklim Organisasi terhadap KinerjaPegawai

Tata 
UsahaAdministrasi UPN "Veteran"

Banjarmasin

Uma Sekaran, 1992, Research Methods for

Business, John Wiley and Son Inc.

Yulk A Gary, 1989, Iklim Organisasi Dalam

Organisasi, alih bahasa Jusuf Udaya,

Penerbit Prenhallindo, Jakarta. 